\begin{tabular}{|c|c|}
\hline Title & Hydrogen desorption behavior of al uminium materials used for extremely high vacuum chamber \\
\hline Author(s) & Hirohata, Y uko; Fujimoto, Satoshi; Hino, Tomoaki; Y amashina, Toshiro \\
\hline Citation & $\begin{array}{l}\text { Journal of V acuum Science \& Technology A: V acuum, Surfaces, and Films, 11(5), 2637-2641 } \\
\text { https://doi.org/10.1116/1.578618 }\end{array}$ \\
\hline Issue Date & 1993-09 \\
\hline Doc URL & http:/hdl.handle.net/2115/5735 \\
\hline Type & article (author version) \\
\hline File Information & JV S\&TA-V SF11-5.pdf \\
\hline
\end{tabular}

Instructions for use 


\title{
Hydrogen desorption behavior of aluminium materials used for extremely high vacuum chamber
}

\author{
Yuko Hirohata, Satoshi Fujimoto, Tomoaki Hino, and Toshiro Yamashina \\ Department of Nuclear Engineering, Faculty of Engineering, Hokkaido University, Kita-13, Nishi-8, Kita- \\ ku, 060 Sapporo, Japan
}

(Received 14 December 1992; accepted 2 April 1993)

\begin{abstract}
Hydrogen desorption properties of pure Al metal $(1050 \mathrm{H} 24$ and $1001 \mathrm{Al})$ and $\mathrm{Al}$ alloy (6063T6) were investigated by using a technique of thermal desorption spectroscopy (TDS). In the TDS spectrum of hydrogen, two peaks in the temperature, which may correspond to the desorptions due to second-order surface reaction and diffusion process, were observed. The activation energy of the desorption, due to the surface reaction for the $1050 \mathrm{H} 24 \mathrm{Al}$, was obtained as $38 \mathrm{~kJ} / \mathrm{mol}$. For the $1001 \mathrm{Al}$, by using a simple diffusion model, the activation energy and diffusion constant of hydrogen due to the diffusion process were calculated as $50 \mathrm{~kJ} / \mathrm{mol}$ and $(0.5-3.5) \times 10^{-3} \mathrm{~cm}^{2} / \mathrm{s}$, respectively. The hydrogen desorption amount of the Al alloy was estimated as $3 \times 10^{15} \mathrm{~mol} / \mathrm{cm}^{2}(0.159 \mathrm{cc} / 100 \mathrm{~g} \mathrm{Al})$, which was twice compared with that of the $1050 \mathrm{H} 24 \mathrm{Al}$. Secondary-ion mass spectroscopy (SIMS) analysis was applied to examine the change of the surface atomic composition after baking. It was found that magnesium was considerably segregated by heating. However, the correlation between the concentrations of hydrogen and magnesium was not clearly observed.
\end{abstract}

\section{INTRODUCTION}

Aluminum or its alloys possess desirable characteristics, e.g., high thermal conductivity, low residual radioactivity, and low desorption rate of gases for numerous applications. ${ }^{1,2}$ Recently, the aluminium alloy or the aluminium metal has been used as an ultra high or extremely high vacuum chamber material. ${ }^{3-5}$ In the range of extremely high vacuum, the major residual gas species is hydrogen. ${ }^{6,7}$ Since the ultimate pressure is determined by the desorption rate of hydrogen from the chamber wall, thus it is important to understand the hydrogen desorption behavior of the aluminium or its alloy.

We, so far, have studied the activation energy of hydrogen desorption and the desorption amount from pure Al metal or Al alloy by using a technique of thermal desorption spectroscopy (TDS) ${ }^{6-8}$ In the present study we examined the activation energies of hydrogen desorption due to surface reaction and diffusion process. For the pure Al (1001A), we also estimated the diffusion rate of hydrogen by using a simple diffusion model.

In order to study the hydrogen concentration at the surface of Al metal or Al alloy, the secondary-ion mass spectroscopy (SIMS) technique was applied. The changes of the hydrogen and the magnesium concentrations due to baking were examined. The relation between the concentrations of hydrogen and magnesium after baking was also discussed.

\section{EXPERIMENTAL}

A TDS-SIMS combined system used in this work is schematically shown in Fig. 1. The system was evacuated both by a turbo molecular pump (TMP) and a Tisublimation pump. An orifice with a diameter of $10 \mathrm{~mm}$ was attached between the vacuum chamber and the pumping system. In this pumping system, a base pressure of
$1.0 \times 10^{-6} \mathrm{~Pa}$ was achieved without baking. During a measurement of TDS spectrum, the chamber was evacuated only by the TMP. Effective pumping speed of the TMP for nitrogen $\left(S_{e}\right)$ was obtained as $9.1 \times 10^{-3} \mathrm{~m}^{3} / \mathrm{s}$. Partial pressures and total pressure were measured by a quadrupole mass spectrometer (QMS) and a Bayard-Alpert (BA) gauge, respectively.

The sample was placed on a Ta heater by using a manipulator with a sample holder. It is possible to set five species on the sample holder. The Ta heater is resistively heated. The temperature was monitored by a chromelalumel thermocouple spotwelded on the Ta heater. The sample was heated up to $500^{\circ} \mathrm{C}$ according to two heating schemes (a) a linear increase of sample temperature, e.g., $B t T=T_{0}+B t$, in which heating rate, $B$, was changed from 3 to $30^{\circ} \mathrm{C} / \mathrm{min}$, and (b) a constant heating temperature. Before and after the TDS measurement for the sample, the background spectrum was measured by heating only for the Ta heater.

Experiments were carried out for pure Al samples $(1050 \mathrm{H} 24,1001)$ and $\mathrm{Al}$ alloy (6063T6) samples. Purities of $1050 \mathrm{H} 24$ and $1001 \mathrm{Al}$ samples were $99.5 \%$ and $99.99 \%$, respectively. Sample geometry was a slab strip of $12 \times 12$ $\times 1.2 \mathrm{~mm}$. Before installation of the sample in the TDS apparatus, the sample was mechanically polished by using alumina powder, rinsed in ethanol in an ultrasonic bath, and dried in air at room temperature.

The SIMS technique was applied to examine the surface concentration of hydrogen. $\mathrm{Ar}^{+}$ion etching was used to measure the atomic depth composition. The energy and current density of the $\mathrm{Ar}^{+}$ions were $5 \mathrm{keV}$ and $10^{-6}$ $\mathrm{A} / \mathrm{cm}^{2}$, respectively. The $\mathrm{Ar}^{+}$ion beam was scanned for the region of $10 \times 10 \mathrm{~mm}^{2}$. The etching rate of $\mathrm{Al}$ was estimated as about $2 \mathrm{~nm} / \mathrm{min}$ from the sputtering data of $\mathrm{Al}^{9}{ }^{9}$ 


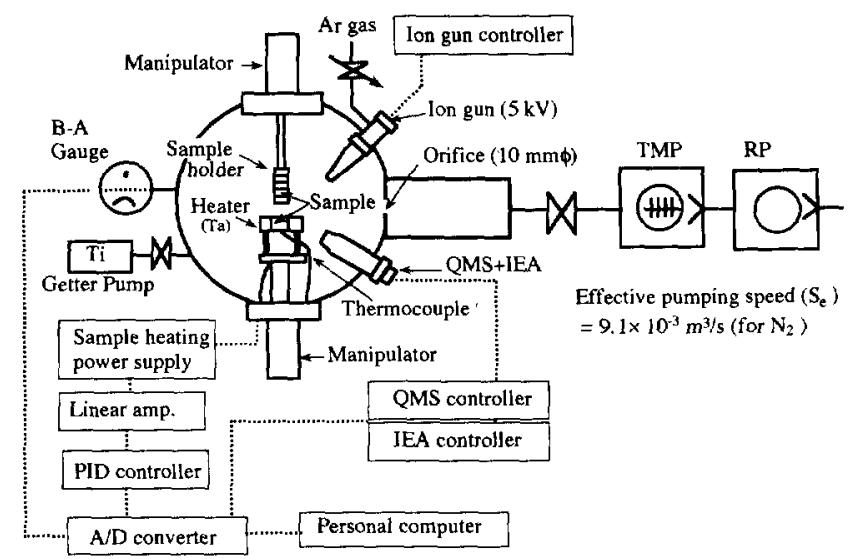

FIG. 1. Schematic diagram of a TDS-SIMS combined system.

\section{RESULTS AND DISCUSSION}

\section{A. Activation energy of hydrogen desorption, and analysis of diffusion rate}

Typical TDS spectra of $1050 \mathrm{H} 24 \mathrm{Al}$ are shown in Fig. 2. Major desorbed gas species were $\mathrm{H}_{2}, \mathrm{H}_{2} \mathrm{O}, \mathrm{CO}, \mathrm{CO}_{2}$, and $\mathrm{CH}_{4}$. The total amount of desorbed hydrogen up to $500{ }^{\circ} \mathrm{C}$ was estimated as $(3-4) \times 10^{15} \mathrm{~mol} / \mathrm{cm}^{2}$, which corresponds to approximately half the total desorption amount of all the gas species.

Two peaks were observed in the TDS spectra except for $\mathrm{CH}_{4}$. From the data of the first peak with peak temperature of $T_{p_{1}}$, the linearity for the determination of activation energy can be obtained, which will be shown later. Thus, it can be presumed that the first peak is due to the surface reaction of hydrogen atoms. For the second peak, no clear explanation on the process has been presented. In this article, we assume that the second peak is associated with diffusion of hydrogen from the bulk including the oxide layer. Figure 3 shows the plot of $\ln \left(T_{p_{1}}^{2} / B\right)$ versus $1 / T_{p_{1}}$ for $\mathrm{H}_{2}$. Here, the data obtained in the same experimental series are indicated as Batch 1 or Batch 2. In spite of the

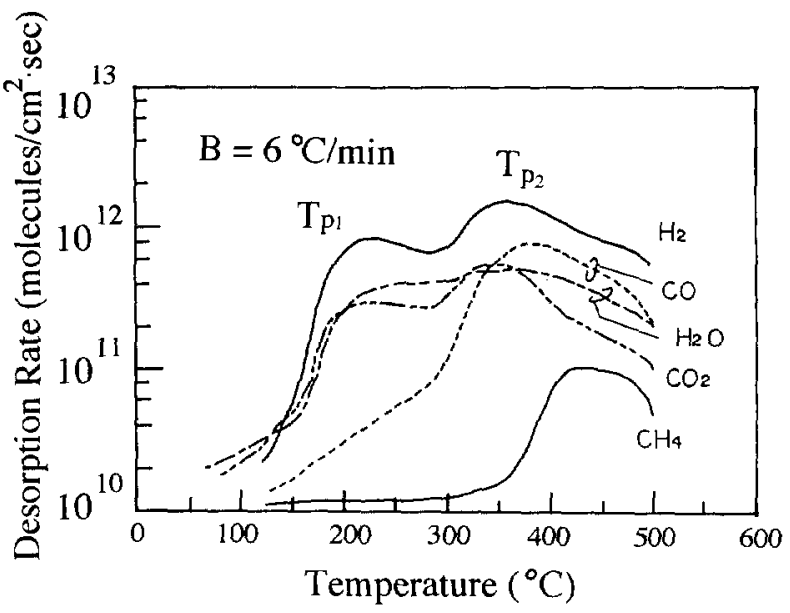

FIG. 2. Thermal desorption curve of pure Al metal (1050H24).

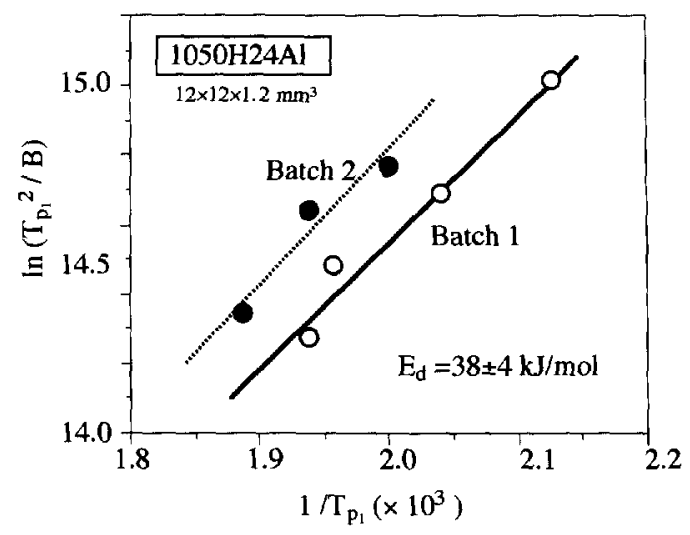

FiG. 3. Reciprocal peak temperature $\left(T_{p_{1}}\right)$ vs $\ln \left(T_{p_{1}}^{2} / B\right)$.

same ramp rate, the value of peak temperature of $T_{p_{1}}$ varied when the experimental series was different. This result indicates that the desorption behavior due to the surface reaction limit is strongly affected by the surface state, such as diffusion, thickness or density of oxide layer, adsorbed species, or impurities, etc. ${ }^{8,10,11}$ However, for the first peak, the linearity between $\ln \left(T_{p_{1}}^{2} / B\right)$ and $1 / T_{p_{1}}$ was found in the every experimental series (batch 1 or batch 2 ). The activation energy was obtained as $38.4 \pm 4.0 \mathrm{~kJ} / \mathrm{mol}$ from the slope of these straight lines. For the second peak, $T_{p_{2}}$, it was difficult to find the linearity between $\ln \left(T_{p_{2}}^{2} / B\right)$ and $1 / T_{p_{2}}$. This may be due to the difference of oxide layer in the samples. So, we investigated the hydrogen desorption behavior for $1001 \mathrm{Al}$ whose purity is higher than that of $1050 \mathrm{H} 24 \mathrm{Al}$. After polishing and rinsing, the sample of $1001 \mathrm{Al}$ was immediately placed into the sample holder and was evacuated to reduce the effect of the formation of oxide layer. The sample geometry was 12 $\times 12 \times 5 \mathrm{~mm}$.

Figure 4 shows the plot of $\ln \left(T_{p}^{2} / B\right)$ versus $1 / T_{p}$ for $\mathrm{H}_{2}$. A linear relation between $\ln \left(T_{p}^{2} / B\right)$ and $1 / T_{p}$ was found for both peaks, e.g., $T_{P_{1}}$ and $T_{p_{2}}$. The activation energies for $T_{p_{1}}$ and $T_{p_{2}}$ were obtained as $21.2 \pm 2$ and

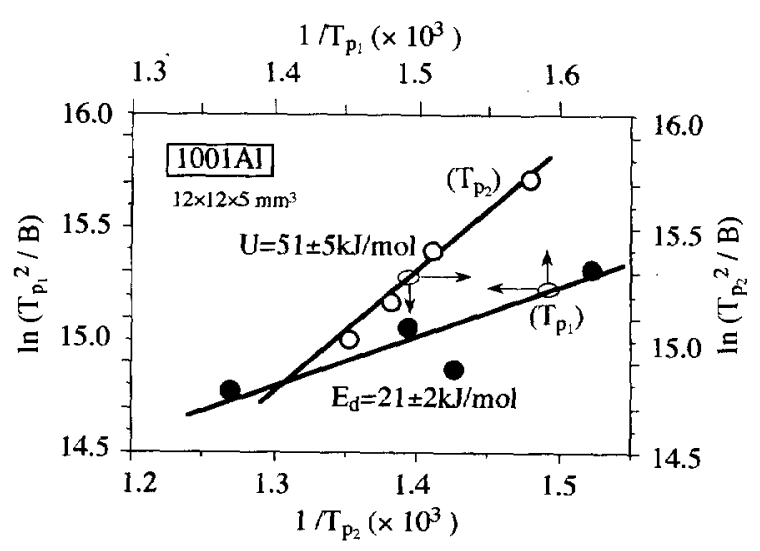

FIG. 4. Relation between $\ln \left(T_{p}^{2} / B\right)$ and $1 / T_{p}$ for $1001 \mathrm{Al}$. 
$50 \pm 5 \mathrm{~kJ} / \mathrm{mol}$, respectively. These values are approximately one-half of that previously reported for the 1060 Al. ${ }^{12}$

Since the desorption behavior of the second peak largely depends on the state of oxide layer, it may be presumed that the hydrogen desorption of the second peak is mainly due to diffusion from the bulk including the oxide layer. In the following we tried to calculate the diffusion rate based upon the obtained activation energy. For this purpose, we consider the following simple diffusion model.

When a sample is heated to a constant temperature, the desorption rate due to diffusion reaction limit, $q(t)$, in the case of a semi-infinite slab sample, is written by

$$
q(t)=\frac{8 C_{0} D}{d} \sum_{0}^{\infty} \exp \left[-\left(\frac{\pi(2 n+1)}{d}\right)^{2} D t\right],
$$

where $\mathrm{C}_{0}$ and $d$ are the initial concentration of hydrogen in an Al sample and the thickness of the slab sample, respectively. $D$ is the diffusion constant. In the case of linear increase of sample temperature, $D$ becomes a function of time, $D(t)$. Then, $D(t)$ is expressed as

$$
D(t)=D_{0} \exp \left(-\frac{U}{k T(t)}\right),
$$

where $U$ and $D_{0}$ are the activation energy of diffusion and a frequency factor, respectively. Since the distribution of the hydrogen concentration in $\mathrm{Al}$ varies with the heating time, the average value of $D(t)$ with respect to the heating time can be used for $D$ in Eq. (1). The average value of $D(t)$ is defined by

$$
Z(t)=\frac{1}{D_{0}} \int D(t) d t=\int \exp \left(-\frac{U}{k T}\right) d t
$$

When the sample temperature is linealy increased, $Z(t)$ is approximated as ${ }^{13}$

$$
Z(t) \approx \frac{k}{B U}\left[T(t)^{2} \exp \left(-\frac{U}{k T(t)}\right)-T_{0}^{2} \exp \left(-\frac{U}{k T_{0}}\right)\right] .
$$

In a case that the diffused hydrogen is immediately desorbed from the surface, the desorption rate becomes

$$
\begin{aligned}
q(t)= & \frac{8 C_{0} D}{d} \exp \left(-\frac{U}{k\left(T_{0}+B t\right)}\right) \\
& \times \sum_{0}^{\infty} \exp \left[-\left(\frac{\pi(2 n+1)}{d}\right)^{2} \frac{D_{0} k(T+B t)^{2}}{B U}\right. \\
& \left.\times \exp \left(-\frac{U}{k\left(T_{0}+B t\right)}\right)\right],
\end{aligned}
$$

where the activation energy is assumed as a constant value.

Figure 5 shows the TDS spectra calculated from Eq. (5). Here, for $U$ and $D_{0}$, the values reported by Eichenauer ${ }^{14}$ were used. The peak temperature, $T_{p}$, shifted to the range of high temperature with an increase of $B$ [Fig. 5(a)], but $T_{p}$ was independent of $C_{0}$ [Fig. 5(b)]. In addition, the shape of the TDS spectrum became asymmetric with respect to $T_{p}$. From this calculation, it was found that the spectrum due to diffusion reaction limit became

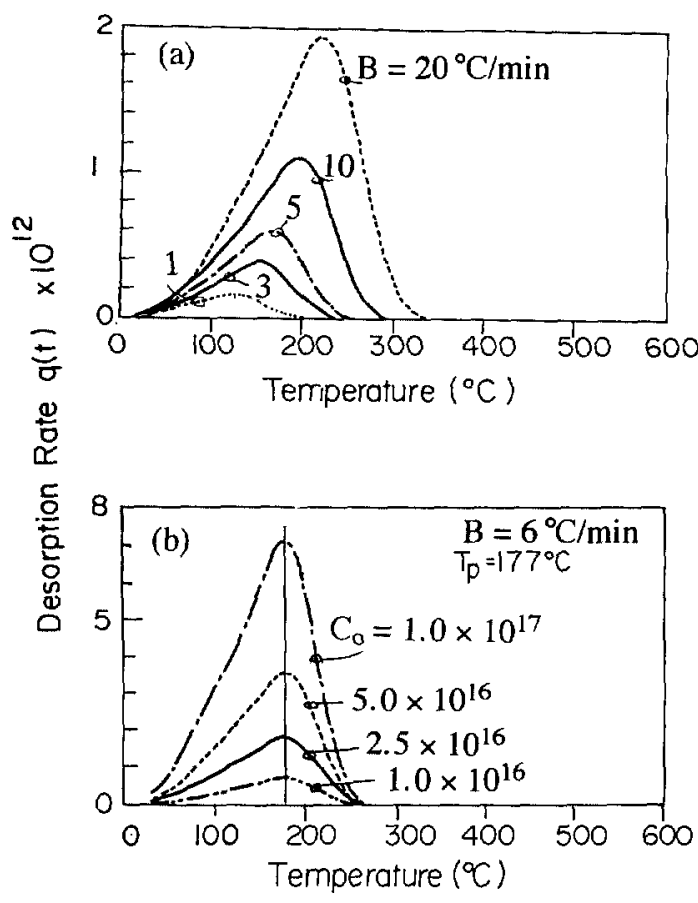

FIG. 5. TDS spectra calculated by using $\mathrm{Eq}$. (5) for different ramp rate, $B$, and the initial concentration of hydrogen, $C_{0}$. (a) $C_{0}=1 \times 10^{16}$ $\mathrm{mol} / \mathrm{cm}^{3}, d=0.1 \mathrm{~cm}, U=40.92 \mathrm{~kJ} / \mathrm{mol}, D_{0}=0.11 \mathrm{~cm}^{2} / \mathrm{s}$; (b) $d=0.1 \mathrm{~cm}$, $U=40.92 \mathrm{~kJ} / \mathrm{mol}, D_{0}=0.11 \mathrm{~cm}^{2} / \mathrm{s}, B=6^{\circ} \mathrm{C} / \mathrm{min}$.

similar to that of the surface reaction limit of first order reaction. We then obtained the activation energy of diffusion from a linear relationship between $\ln \left(T_{p}{ }^{2} / B\right)$ and $1 / T_{p}$, derived from Fig. 5(a). The activation energy obtained from the plot well agreed with the Eichenauer data. Thus we confirmed that the present model is selfconsistent.

The activation energy of the diffusion for hydrogen experimentally observed was $50 \pm 5 \mathrm{~kJ} / \mathrm{mol}$. The frequency factor, $D_{0}$, became $(0.5-3.5) \times 10^{-3} \mathrm{~cm}^{2} / \mathrm{s}$ from the numerical simulation. In the simulation, $U$ was assumed as constant $(50 \pm 5 \mathrm{~kJ} / \mathrm{mol})$ and $D_{0}$ be fitted to the peak temperature of the desorption. The value of the diffusion rate, $D$, experimentally obtained by numerous authors. ${ }^{15}$ The values for $U$ and $D_{0}$ have the ranges from 40 to 60 $\mathrm{kJ} / \mathrm{mol}$, and from $10^{-3}$ to $1 \mathrm{~cm}^{2} / \mathrm{s}$, respectively. The diffusion rate, $D$, at temperature of $100^{\circ} \mathrm{C}$ has a wide range from $5.6 \times 10^{-11}$ to $3.02 \times 10^{-7} \mathrm{~cm}^{2} / \mathrm{s}$. The present values for $U$ and $D_{0}$ obtained in our experiment became similar, e.g., activation energy was $50 \mathrm{~kJ} / \mathrm{mol}$ and diffusion rate at temperature of $100^{\circ} \mathrm{C}$ was from $1.8 \times 10^{-9}$ to $3.0 \times 10^{-10}$ $\mathrm{cm}^{2} / \mathrm{s}$.

\section{B. Amount of desorbed hydrogen}

Desorption spectra of hydrogen from the Al metal $(1050 \mathrm{H} 24)$ and the Al alloy (6063T6) at a constant temperature of $500{ }^{\circ} \mathrm{C}$ are shown in Fig. 6. The background spectra before and after the TDS experiment are also shown by dotted and broken lines, respectively. The desorption rate of hydrogen from the $\mathrm{Al}$ metal increased rap- 


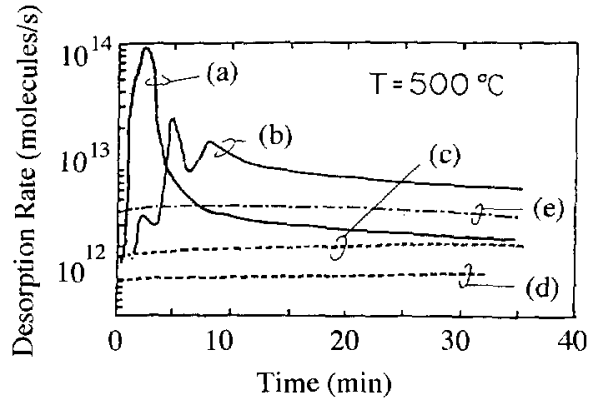

FIG. 6. Hydrogen desorption curves of $1050 \mathrm{H} 24 \mathrm{Al}$, and $6063 \mathrm{Al}$ alloy and the background. (a) TDS curve of $1050 \mathrm{H} 24 \mathrm{Al}$, (b) TDS curve of $6063 \mathrm{~T} 6 \mathrm{Al}$ alloy, (c) background of $1050 \mathrm{H} 24$ before and after heating, (d) background of $6063 \mathrm{~T} 6$ before heating, (e) background of $6063 \mathrm{~T} 6$ after heating.

idly within several minutes and after that continuously decreased. After $30 \mathrm{~min}$, the desorption rate decreased to the background level.

Three peaks were observed in the spectrum of the Al alloy. The desorption rate of the $6063 \mathrm{~T} 6 \mathrm{Al}$ was rather smaller than that of the $1050 \mathrm{H} 24 \mathrm{Al}$ in the initial heating phase, but even after heating for $30 \mathrm{~min}$, the desorption rate did not approach the background level. After the TDS experiment of $\mathrm{Al}$ alloy, the background level became larger than that before the TDS experiment. This behavior, e.g., the appearance of three peaks and the enhancement of background level, may be caused by the formation of a $\mathrm{Ta}-\mathrm{Mg}$ alloy on the surface of a $\mathrm{Ta}$ heater due to the evaporation of magnesium from the $\mathrm{Al}$ alloy. The $\mathrm{Ta}-\mathrm{Mg}$ alloy is well known as a hydrogen-storage material. In order to obtain the amount of desorbed hydrogen from $\mathrm{Al}$ alloy, it is necessary to add the desorption amount of hydrogen from the Ta heater alone.

The total amount of hydrogen desorbed from the Al alloy was estimated as about $2.0 \times 10^{16} \mathrm{~mol}(0.159 \mathrm{cc} / 100$ $\mathrm{g} \mathrm{Al}$ ) by integrating the desorption spectrum with respect to time. This value was two times larger than that of $1050 \mathrm{H} 24 \mathrm{Al}$. On the other hand, this value was one-half the value reported by Imabayashi $(0.25 \mathrm{cc} / 100 \mathrm{~g} \mathrm{Al}$ and Al alloy heated up to $\left.700{ }^{\circ} \mathrm{C}\right)^{16}$ or by Kato $(0.36 \mathrm{cc} / 100 \mathrm{~g} \mathrm{Al}$ heated up to $\left.900^{\circ} \mathrm{C}\right) .{ }^{17}$ This difference may be explained,
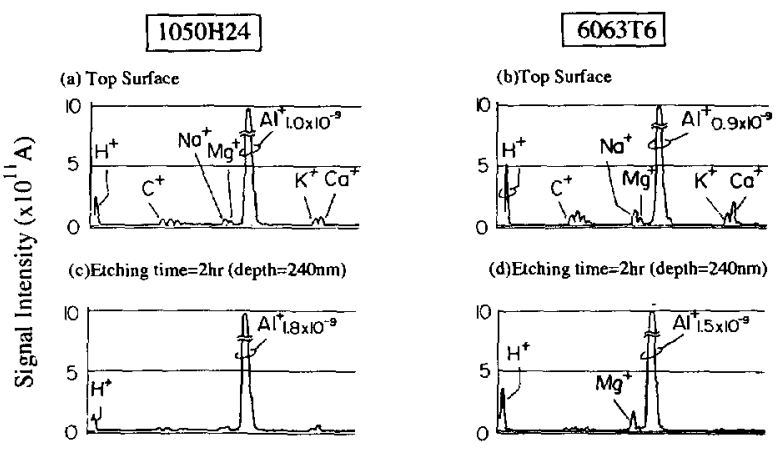

FIG. 7. SIMS spectra of $1050 \mathrm{H} 24 \mathrm{Al}$ and $6063 \mathrm{~T} 6 \mathrm{Al}$ alloy before and after etching with $\mathrm{Ar}^{+}$ion.
TABLE I. The amount of desorbed hydrogen from pure $\mathrm{Al}$ and $\mathrm{Al}$ alloy samples.

\begin{tabular}{lcccc}
\hline & \multicolumn{2}{c}{ Pure Al samples } & & Al alloy sample \\
\cline { 2 - 3 } Type & 1001 & $1050 \mathrm{H} 24$ & & $6063 \mathrm{~T} 6$ \\
\hline $\begin{array}{l}\text { Desorption } \\
\text { amount } \\
(\mathrm{cc} / 100 \mathrm{~g} \mathrm{Al})\end{array}$ & 0.04 & 0.088 & 0.159 \\
\hline \hline
\end{tabular}

because in the present experiment the temperature was not high enough for the Al to be melted and the heating time was not long enough for the hydrogen to be desorbed perfectly.

Table I shows the amount of hydrogen desorbed from pure Al and Al alloy during heating at a temperature of $500^{\circ} \mathrm{C}$ for $30 \mathrm{~min}$. It was found that the sample with a smallest amount of desorbed hydrogen was $1001 \mathrm{Al}$. The present data on the relationship between $6063 \mathrm{~T} 6 \mathrm{Al}$ and $1050 \mathrm{H} 24 \mathrm{Al}$ at low temperature agrees with the data obtained by Chen and co-workers ${ }^{1}$ and Narushima. ${ }^{12}$

\section{Relation between surface concentrations of hydrogen and magnesium}

For $6063 \mathrm{~T} 6 \mathrm{Al}$ alloy and $1050 \mathrm{H} 24 \mathrm{Al}$, SIMS analysis was applied to examine the change of surface composition. The SIMS spectra on the top surface and near surface region were shown in Fig. 7. The signal intensity of $\mathrm{H}^{+}$for Al alloy was larger than that of the Al metal both at the top surface and the region in the depth of about $240 \mathrm{~nm}$. This result was consistent with the TDS data.

If $\mathrm{Al}$ alloy is used as a vacuum chamber material, the baking temperature must be kept lower than $150^{\circ} \mathrm{C}$ because of low melting point of $\mathrm{Al}$ alloy. We then examined the change of surface composition of $\mathrm{Al}$ alloy during baking by using SIMS technique. Figure 8 shows the signal intensities of $\mathrm{Mg}^{+}$and $\mathrm{H}^{+}$for the $6063 \mathrm{~T} 6 \mathrm{Al}$ alloy heated at a temperature $150^{\circ} \mathrm{C}$. The intensity of $\mathrm{Mg}^{+}$on the surface gradually increased with the heating time, about eight times enhanced compared with the case before heating. The thickness of the alternated layer was roughly $60 \mathrm{~nm}$.

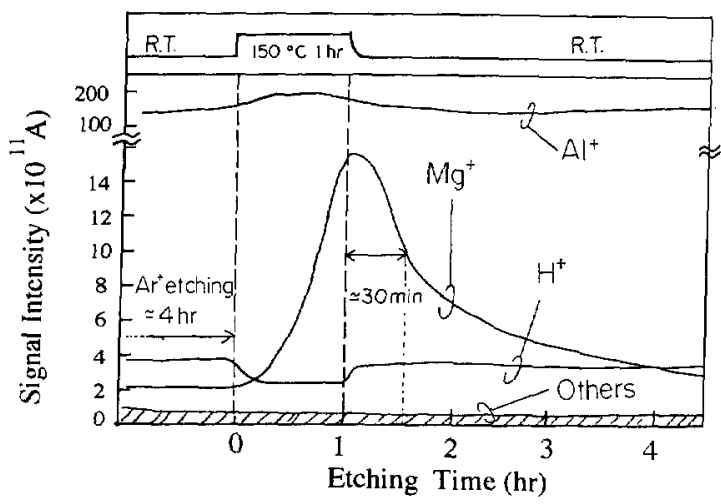

FIG. 8. Surface analysis of $6063 \mathrm{~T} 6 \mathrm{Al}$ alloy heated at $150^{\circ} \mathrm{C}$ and cooled at room temperature during $\mathrm{Ar}^{+}$ion etching. 


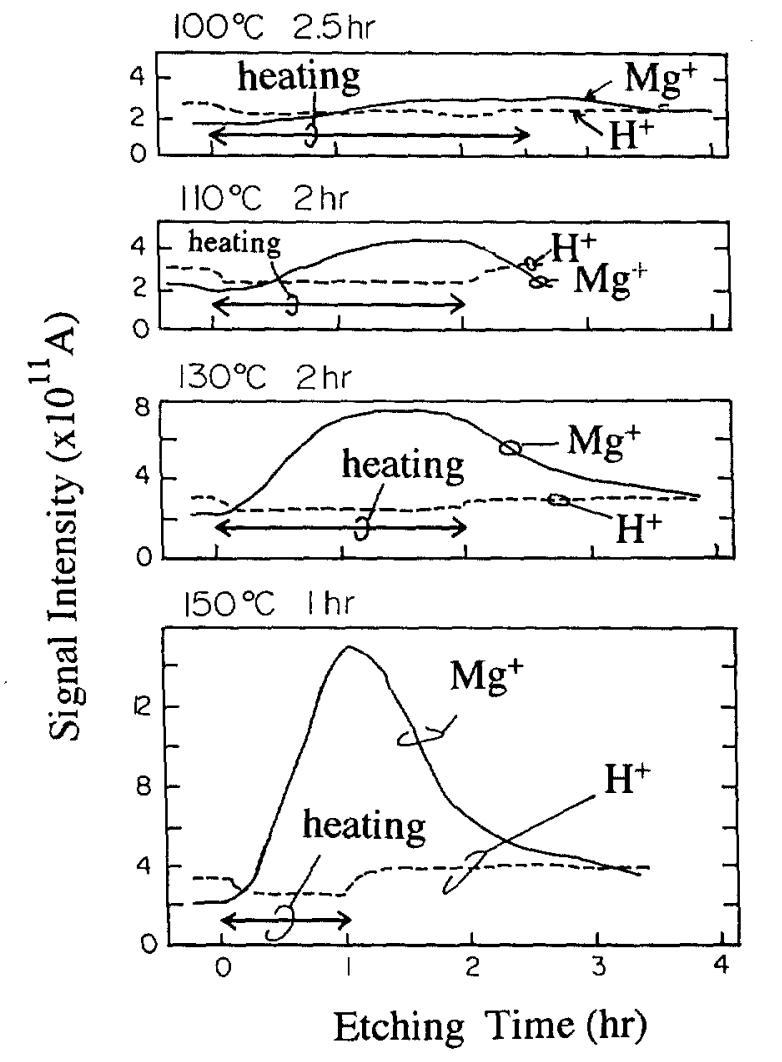

FIG. 9. Changes of SIMS signal intensities of $\mathrm{Mg}^{+}$and $\mathrm{H}^{+}$with different heating conditions.

The signal intensity of $\mathrm{H}^{+}$became small during heating, but after heating it returned to the previous level. Figure 9 shows the signal intensities of $\mathrm{Mg}^{+}$and $\mathrm{H}^{+}$of $\mathrm{Al}$ alloy heated at different heating conditions. The segregation of $\mathrm{Mg}$ became large with increase of the heating temperature. The ratio of signal intensities of $\mathrm{H}^{+}$to $\mathrm{Al}^{+}$was almost the same for each baking schedule. The hydrogen concentration on the surface was observed to be independent of the magnesium concentration. It can be assumed that the amount of hydrogen on the surface due to readsorption is already saturated, since the hydrogen amount did not increase with magnesium concentration.

\section{CONCLUSION}

A TDS technique was applied to investigate the hydrogen desorption behavior of Al materials. The amount of $\mathrm{H}_{2}$ desorbed from the $\mathrm{Al}$ alloy during heating at $500^{\circ} \mathrm{C}$ for 30 min became $0.159 \mathrm{cc} / 100 \mathrm{~g}$, which was twice and four times larger than those of $1050 \mathrm{H} 24 \mathrm{Al}$ and $1001 \mathrm{Al}$, respectively. The activation energy of desorbed hydrogen due to the hydrogen recombination was estimated as $38.4 \pm 4$ $\mathrm{kJ} / \mathrm{mol}$ for the $1050 \mathrm{H} 24 \mathrm{Al}$. For the $1001 \mathrm{Al}$ sample, the diffusion rate was obtained as $D=(0.5-3.5)$ $\times 10^{-3} \exp [50 \pm 5(\mathrm{~kJ} / \mathrm{mol}) / \mathrm{RT}]\left(\mathrm{cm}^{2} / \mathrm{s}\right)$ by using a simple diffusion model.

The segregation of magnesium became dominant during the baking at temperature of $150^{\circ} \mathrm{C}$. However, the concentration of magnesium in the surface had no relation to the surface concentration of hydrogen. In present experimental condition, it is presumed that the magnesium has no gettering action for hydrogen.

\section{ACKNOWLEDGMENT}

The authors wish to thank the Light Metal Foundation in Japan for their financial support of this work.

${ }^{1}$ J. R. Chen, K. Narushima, and H. Ishimaru, J. Vac. Sci. Technol. A 3, 2188 (1985).

${ }^{2}$ S. Ueda, Y. Ishikawa, and H. Kamohara, Jpn. J. Vac. Soc. 31, 976 (1988).

${ }^{3}$ H. Ishimaru, K. Narushima, K. Kanazawa, and Y. Suetsugu, J. Vac. Sci. Technol. A 6, 1293 (1988); H. Ishimaru, ibid. 7, 2439 (1989).

${ }^{4}$ T. Kikuchi and S. Ohsako, Jpn. J. Vac. Soc. 33, 72 (1990).

${ }^{5}$ A. G. Mathewson, J.-P. Bacher, K. Booth, R. S. Calder, G. Domininchini, A. Grillot, N. Hilleret, D. Latorre, F. LeNormand, and W. Unterlerchner, J. Vac. Sci. Technol. A 7, 77 (1989).

${ }^{6} \mathrm{P}$. Redhead, Vacuum 12, 203 (1962).

${ }^{7}$ G. Carter, Vacuum 12, 245 (1962).

${ }^{8}$ T. Tai, Y. Muroo, and O. Konno, Japan J. Vac. Soc. 33, 514 (1990).

${ }^{9}$ K. Tsunogaya, T. Suzuki, Y. Ohashi, and H. Kishidaka, Surf. Interface Anal. 2, 212 (1980).

${ }^{10}$ Y. Kato, E. Isoyama, and M. Hasegawa, Jpn. J. Light Metals 38, 462 (1988).

${ }^{11}$ Y. Hirohata, M. Hashiba, T. Hino, and T. Yamashina, Bull. Fac. Eng. Hokakido Univ. No. 15871 (1992), No. 15919 (1992).

${ }^{12}$ K. Narushima and H. Ishimaru; Jpn. J. Vac. Soc. 26, 353 (1983).

${ }^{13}$ Y. Hirohata, Jpn. J. Vac. Soc. 33, 488 (1990).

${ }^{14}$ W. Eichenauer and A. Pebler, Z. Metall. 48, 373 (1957).

${ }^{15}$ K. Watanabe, K. Ashida, and M. Sonobe, J. Nucl. Mater. 173, 294 (1990).

${ }^{16}$ M. Imabayashi, Jpn. J. Light Metals 23, 38 (1973)

${ }^{17}$ Y. Kato, T. Kitamura, E. Isoyama, and M. Hasegawa, J. Vac. Sci. Technol. A 6, 3111 (1988). 